\section{4 \\ CONTROL OF ENVIRONMENT IN HORTICULTURE}

$\mathrm{O}^{\mathrm{N}}$ September 13, Section M (Agriculture) of the British Association held a discussion on "Control of Environment in Horticulture", over which Prof. H. D. Kay presided.

Dr. W. F. Bewley opened with a paper on "The Control of Heat and Light in Glasshouses". Hie pointed out that although plants in glasshouses are warmer and more sheltered than those in the open, the light intensity is reduced, moisture tends to accumulate, and crop rotation is scarcely possible. So the owner of glasshouses has problems to face which have no parallel in field cultivation.

The action of light must be considered in two different ways, namely, its photosynthetic effect on the production of carbohydrates with the consequent increase in growth, and its photoperiodic effect in deciding the actual time of flowering. Dealing with the former and referring to workers in the United States, Holland and Britain, he pointed out that by irradiating seedlings and young plants for three or four hours at the end of the day, it is possible to stimulate growth considerably, and in the case of cucumbers to achieve a worthwhile increase in crop. The main facts emerging from the experiments are that a high light intensity, 300-400 foot candles, is necessary, that the effect is mainly upon young plants and that the cost of the apparatus is high. The work has not yet reached a stage at which it could be recommended to commercial growers.

In photoperiodism, the case is much different, for by adjusting the length of day either by darkening or irradiating the plants, it is possible to retard or advance the flowering of many plants; and in the case of chrysanthemums to produce flowers for market at any time of the year. The apparatus is cheap, the duration of illumination short, and the process effective. $\mathrm{He}$ suggested that the assistance of physicists and engineers is necessary to solve the problem of light supply to increase growth and crop production, and that large-scale illumination from high-power lamps above the ranges of glasshouses might provide the solution. Until this is achieved, growers should site their nurseries in districts where winter light is at a maximum, glasshouse builders should design better lighted houses, and east-towest houses should be built for propagating young plants and for growing pot plants during the winter.

Turning to the question of heat, Dr. Bewley said that considerable progress has already been made in thermostatic control. It is now possible to maintain a constant night temperature by applying thermostatic control to all systems of heating, including highand low-pressure steam, steam-cum-water, oil-fired boilers, gravity feed and under-feed stokers using solid fuel. Despite these improvements, however, he said little has been done to cool the glasshouses during the summer, and he hoped the engineers would help.

On the subject of soil warming, he discussed the relative values of electrically heated wires and hot water eirculated through small pipes. Soil-warming experiments have shown that raising the soil temperature provides bigger and cleaner roots, better plants, heavier crops and earlier maturity.

In conclusion, Dr. Bewley concluded that temperature control of glasshouses has already made good progress, but that control of light is still a problem for the future.

Mr. Raymond Bush, who followed with a paper on "Frost and the Fruitgrower", said that prior to 1935 no real attention had been given in Britain to May frosts. Indeed, the East Malling conference held that year showed very clearly that no one knew very much about them. From his extensive investigations, Mr. Bush gave many examples of frost injury which showed very clearly that cold air follows to some extent the behaviour of water in flowing over the land; it follows the contours, settling in valleys and hollows generally, or draining through them without causing damage. In view of the way in which great variations in crop production can be attributed to frost, he urged the necessity for selecting the correct site when planning new plantations, and expressed the view that areas of land suitable for future development should be earmarked for this purpose. So many orchards, however, are so badly sited that it is now a question of fighting the frosts and not preventing them. In this respect Mr. Bush discussed the value of shelter belts, but pointed out that they should contain gaps through which the cold air could drain away to levels below the orchards.

The talk was admirably illustrated with lantern slides. By this means, Mr. Bush gave a clear picture of the present attempts to fight frosts both in America and in Great Britain. He discussed the use of heater pots, the movement of air by mechanical means, including the helicopter, and the use of smoke generators and infra-red lamps. In conclusion, he was careful to point out that the wise choice of a site is still of fundamental importance.

The last paper, by Mr. F. A. Secrett, was on "Horticultural Crops in their Relationship to Water". Mr. Secrett said that the present world food shortage demands that the best use must be made of all available land, and that if the weight per acre could be increased, more land would be freed for other crops. He argued that as the growth of plants varies directly in accordance with the water supply, we experience gluts in wet weather and shortages in dry weather. Further, dry spells in the summer cause delay in sowing or planting the second crop. Armed with an efficient irrigation plant, growers are independent of rain. They can produce better crops of higher quality vegetables and continue their cropping programme unhindered by dry weather. Indeed, he claimed that some crops can be doubled in weight where watered overhead, especially if a little soluble nitrogen is added to the water.

Mr. Secrett discussed in detail the results of experiments on his farm carried out in co-operation with Rothamsted Experimental Station. For example, the application of $4 \mathrm{in}$. of water increased the yield of carrots by 20 per cent. Sugar beet producing 20 tons of roots in the control plot gave 29 tons in plots receiving $10 \mathrm{in}$. of water by overhead irrigation, and in addition to this the sugar content was increased considerably. Speaking on the question of quality, Mr. Secrett claimed that when vegetables are irrigated correctly they improve in flavour, and gave examples of this in the case of radish, lettuce and cauliflower. Overhead irrigation is a very valuable process in the hands of the grower.

The advantages of overhead irrigation are many. The grower is independent of rain, and can continue to carry out his crop programme and cultivations in the driest weather. Quality is improved, weight of crop per acre is increased, a high plant population 
is possible, and pests due to drought are controlled. Soluble fertilizers can be added to the water and minor elements also supplied in this way. Production is speeded up and a greater variety of vegetables can be grown.

The discussion was opened by Lord Bledisloe, who was followed by Sir John Russell and others. In replying to questions Dr. Bewley said that, whereas glasshouse growers as a whole are not attracted by cloches, new entrants into horticulture are learning how to use them and many seem satisfied with the results. He thought that no objection could be raised to steel houses on the basis of more severe temperature fluctuations. He had examined most glass-substitute materials, and while some are satisfactory for a year or two, those that are cheap enough for commercial purposes do not stand up to weather conditions very long. $\mathrm{He}$ had long been interested in waste heat from power stations and factories. Usually the waste hot water is not hot enough for circulating in the glasshouse pipes, and there is the disadvantage of injurious fumes and grit owing to the close proximity of the industrial plant.

Mr. Bush, in reply to questions, emphasized that shelter belts should always contain gaps through which the cold air can drain away. The lime makes a good shelter belt, but must not be too dense.

Mr. Secrett said that the addition of nitrate of potash in the irrigation water had always given better results than nitrate of soda, but he could not say why. It was perhaps surprising that the very small amounts of fertilizers used in the water had such big effects, but it was probably due to the repeated applications. There is no limit to the area that can be irrigated provided the spray lines are available. His units are four acres, and at Milford he irrigated twenty acres from one centre.

\section{INTER-UNIVERSITY RELATIONS AND EXCHANGES}

$\mathrm{T}$ HE question of inter-university relations, which was discussed on July 21 at the Congress of Universities of the Commonwealth, is partly an administrative and partly an academic question. On one hand, it is necessary to make such business arrangements between the universities as will enable a young student or teacher to move from one university to another without academic loss of standing or financial embarrassment. On the other, it is necessary to make such an exchange sufficiently attractive from an academic point of view for the man or woman contemplating a temporary migration to make sure that it will be academically advantageous. No young man with academic ambitions - which will probably be centred in his own countrywill welcome the idea of an exchange which will leave him for a year in a university which is not equipped whether in its libraries or laboratories to enable him to develop his own research. Conversely, no university will welcome a teacher who regards himself as nobly and self-sacrificingly spreading the joys of learning to universities less lucky than his own.

This latter problem can only be met by the universities knowing each other better. Though many of the speakers at the Congress admitted that their universities were ill-equipped for certain types of work, almost all were able to claim that in one subject or another they were doing work, or had work waiting to be done, which would be most attractive to a young teacher anxious to become master of some topic. The vast quantity of work awaiting the historian of Australia is an example. The first essential is that the universities should know each other far more intimately than they do at present. The Congress agreed to recommend that the universities of each country should be encouraged to form an agency which should act as an instrument of communication with universities elsewhere. Further, since the whole Congress meets only every five years, it was suggested that, in the years between such meetings, vice-chancellors and senior members of staff should visit each other as frequently and as. regularly as possible.

The Congress passed several resolutions designed to make the traffic between universities easier and less hazardous. The first resolution dealt with the announcement and advertising of vacancies. It is in this stage that the central office of the Universities Bureau can be of great assistance. It can keep in touch with the appointments committees of the several universities and provide information about the type of post to be filled. It can arrange for candidates to be interviewed by a panel composed both of experts in any subject and of men acquainted with the university which is advertising a vacancy. It can arrange for the successful candidate to be given expert advice about what he may expect to find at the university to which he is going. But it cannot fulfil these functions unless it is very fully informed of the needs of the advertising universities. Many posts are filled by a local man although the formality of advertising may be maintained. It is obviously undesirable in these cases to put candidates to the expense and inconvenience of applying for $a$ vacancy which is more nominal than actual. But if the Bureau receives the help it needs, it can be of immense use to any universities arranging exchanges.

The second resolution dealt with the question of superannuation benefits. Though the importance of ensuring that a man does not suffer financial loss if he goes temporarily to another university needs no stressing, the method of achieving this end is extremely complicated. A committee was set up to inquire into the possibilities.

The question of travelling expenses is closely related. The cost of moving from one part of the Commonwealth to another is in itself sufficient to make the idea impossible for most aspirants. It was agreed to approach bodies or foundations which may have resources available for this purpose; and the Congress was given to understand that proposals would be sympathetically received by some at least of these foundations. It is quite certain that no exchanges can be successfully arranged unless the finances are arranged in such a way as to make the project if not attractive at least reasonable, from the point of view of the scholar or student who is contemplating migration.

The Congress had before it a report written by Mr. Douglas Veale, registrar of the University of Oxford. Mr. Veale has recently been in Australia and wrote an account of his visit and put forward several recommendations as a result of what he had learned. As his memorandum took the form of $a$ report to his own University, it was not discussed by the Congress; but it included the greater part of what the delegates to the Congress were seeking, 